\title{
STIMULATED WHOLE BLOOD CYTOKINE RELEASE AS A BIOMARKER OF IMMUNOSUPPRESSION IN THE CRITICALLY ILL: THE NEED FOR A STANDARDIZED METHODOLOGY
}

\author{
Elisabetta Segre and James N. Fullerton \\ Centre for Clinical Pharmacology, Division of Medicine, University College London, London, UK
}

Received 23 Nov 2015; first review completed 8 Dec 2015; accepted in final form 22 Dec 2015

\begin{abstract}
Objective: Reduced ex vivo lipopolysaccharide (LPS) stimulated whole blood pro-inflammatory cytokine release is a hallmark of immunosuppression in the critically ill and predicts adverse clinical outcomes. No standard technique for performing the assay currently exists. The impact of methodological heterogeneity was determined. Design, Setting, Subjects, and Interventions: Clinical experimental study set in a research laboratory. Venous blood from 5 to 10 healthy volunteers/experiment (total participant group: 18 subjects, $72 \%$ men, mean age 32 ) was stimulated ex vivo to evaluate the effect of variables identified via literature review on tumor necrosis factor- $\alpha$ (TNF $\alpha$ ) release. These included sample handling, stimulation technique, and incubation conditions. Reporting convention was additionally assessed. Main Results: Measured TNF $\alpha$ release was significantly altered by source of LPS, concentration of LPS employed, duration and temperature of incubation prior to supernatant aspiration, and predilution of blood (repeated measures ANOVA, all $P<0.01$ ). Sample handling prior to stimulation (anticoagulant employed, time to LPS addition, and storage temperature) also caused significant alterations in TNF $\alpha$ release. Considerable interindividual variation was observed (range 1,024-4,649 $\mathrm{pg} / \mathrm{mL}$, mean $2,339 \mathrm{pg} / \mathrm{mL}$ ). Normalization by monocyte count and pretreatment with a cyclooxygenase inhibitor (indomethacin $10 \mu \mathrm{M}$ ) reduced the coefficient of variation from $47.17 \%$ to $32.09 \%$. Conclusions: Inconsistency in interlaboratory methodology and reporting impairs interpretation, comparability, and reproducibility of the ex vivo LPS-stimulated whole blood cytokine release assay. A standardized validated technique is required. The advent of trials of immunoadjuvant agents renders this a clinical imperative.
\end{abstract}

KEYWORDS_Diagnostic, endotoxin tolerance, immunoadjuvant, lipopolysaccharide, sepsis, stratified medicine, therapeutics, tumor necrosis factor $\alpha$

\section{INTRODUCTION}

Late mortality in critically ill patients with severe sepsis, or following trauma, burn or major surgery, is now thought due to the predominance of anti-inflammatory processes. Whether excessive, sustained, or secondary to a failure of the immune system to recover from their functional consequences, the net effect is one of immunosuppression characterized by susceptibility to opportunistic infection and acquisition of secondary sepsis $(1,2)$. Therapeutically, this may be addressed via augmentation of the immune system with immunoadjuvant agents (3), an approach that has demonstrated initial promise in selected septic patients $(4,5)$.

Address reprint requests to Dr James N. Fullerton, Wellcome Trust Research Training Fellow, Specialist Registrar in Clinical Pharmacology and Therapeutics, Division of Medicine, Rayne Institute, 5 University Street, University College London, London WC1E 6JF, UK. E-mail: james.fullerton@ doctors.org.ukThe work presented here was undertaken in the Centre for Clinical Pharmacology, Division of Medicine, University College London, UK.

JNF is a Wellcome Trust Clinical Research Fellow and the research presented was funded by this award. JNF is in receipt of additional funding from an Investigator Initiated Research award made by Pfizer.

The authors report no conflicts of interest.

Supplemental digital content is available for this article. Direct URL citation appears in the printed text and is provided in the HTML and PDF versions of this article on the journal's Web site (www.shockjournal.com).

DOI: $10.1097 /$ SHK.0000000000000557

Copyright (C) 2015 by the Shock Society. This is an open access article distributed under the Creative Commons Attribution License 4.0 (CCBY), which permits unrestricted use, distribution, and reproduction in any medium, provided the original work is properly cited.
The key to an immunorestorative strategy is patient stratification-identifying individuals with clinically meaningful immunosuppression who may benefit from treatment. To date, two interrelated biomarkers have repeatedly proven predictive of acquisition of both nosocomial infection and mortality and have consequently been used to guide inclusion in clinical trials: monocyte human leukocyte antigen DR (mHLA-DR) expression $(6,7)$ and ex vivo lipopolysaccharide (LPS)-stimulated whole blood (WB) tumor necrosis factor $\alpha(\mathrm{TNF} \alpha)$ release $(8-10)$. While a standardized methodology and reporting tradition has been established for mHLA-DR (11), the same is not true for $e x$ vivo cytokine release, potentially leading to disparities in case definition, identification, treatment allocation, and outcome determination that impair data interpretation and comparability.

This study sought to identify key inter-laboratory differences in sample handling, technical performance of the $\mathrm{WB}$ ex vivo cytokine release assay, and result reporting convention, determining their impact on measured TNF $\alpha$ and hence quantification of immune competence.

\section{MATERIALS AND METHOD}

\section{Study design, setting, and subjects}

Eighteen healthy volunteers (13 men [72.2\%], mean age 32 years) were recruited, 5 to 10 individuals participating in each experiment dependent on the variable evaluated. All samples were obtained and processed in a clinical research laboratory. Ethical approval for the protocol was provided by the University College London Research Ethics Committee (project ID: 4332/001). 


\section{Data collection}

Health Volunteer Blood: Venous blood was collected and stored in lithium heparin (LH, Grenier Bio-One Vacuette), ethylenediaminetetraacetic acid (EDTA), or sodium citrate (Na Cit, both BD Biosciences Vacutainer) containing tubes prior to stimulation.

Stimulation: Unless otherwise stated $1 \mathrm{~mL}$ heparinized WB was diluted 1:5 in RPMI (Gibco, Grand Island, NY) in $15 \mathrm{~mL}$ polypropylene tubes (Fisher Scientific, Grand Island, NY) and stimulated for $6 \mathrm{~h}\left(37^{\circ} \mathrm{C}, 250 \mathrm{rpm}\right)$ with $1 \mathrm{ng} /$ mL LPS (Salmonella abortus equi S-form [TLRgrade], Enzo Life Sciences, Farmingdale, NY), after Kox et al. (12). Blood was stimulated within 30 min of draw. After incubation samples were centrifuged at $2000 \mathrm{~g}$ for $10 \mathrm{~min}$ at $20^{\circ} \mathrm{C}$ and supernatant stored at $-80^{\circ} \mathrm{C}$. Three technical repeats (tubes/individual/ condition or time-point) were performed.

Variables: On the basis of the results of the literature review the core technique was modified to evaluate the effect of LPS type (Escherichia coli 0111:B4 and 055:B5 [Sigma-Aldrich, St. Louis, Mo], Salmonella abortus equi, Salmonella Minnesota R-form serotype: R595 [Hycult]), LPS concentration (1 $\mathrm{pg} / \mathrm{mL}$ to $100 \mathrm{ng} / \mathrm{mL}$ Salmonella abortus equi), duration of stimulation ( $30 \mathrm{~min}$, $1,2,4,6,8,24 \mathrm{~h}$ ), anticoagulant employed (LH, EDTA, Na Cit), incubation conditions (temperature $\left[20^{\circ} \mathrm{C}\right.$ vs. $\left.37^{\circ} \mathrm{C}\right]$, agitation [0 rpm vs. $\left.250 \mathrm{rpm}\right]$ ), sample dilution (none, 1:1, 1:5, 1:10), and sample handling (time to stimulation $[2,4,6$, $12 \mathrm{~h}]$, storage temperature $\left.\left[4^{\circ} \mathrm{C}, 20^{\circ} \mathrm{C}, 37^{\circ} \mathrm{C}\right]\right)$. In addition, the effect of pretreating the blood with a non-steroidal anti-inflammatory drug (indomethacin $10 \mu \mathrm{M}$ [Sigma-Aldrich], a dual cyclooxygenase 1 and 2 inhibitor) was evaluated. Where not supplied in solution LPS was reconstituted in sterile deionized water and vortexed extensively prior to use.

$\mathrm{TNF} \alpha$ and Monocyte Quantification: The concentration of $\mathrm{TNF} \alpha$ was determined via enzyme-linked immunosorbent assay according to the manufacturer's instructions (Duoset, R\&D systems, Minneapolis, MN). Differential leucocyte counts were performed via a Sysmex XE2100 flow cytometric analyzer by The Doctors Laboratory (London, UK).

\section{Statistical analysis}

Data points represent the average of three technical repeats, each assayed in duplicate. The D'Agostino-Pearson test was used to test for normality. Differences between categorical variables were tested for using either repeated measures one-way or two-way analysis of variance (RM-ANOVA, incorporating the Greenhouse-Geisser correction) with Tukey multiple comparisons test, or paired $t$ tests. Statistical significance was set at $P<0.05$. All analyses were conducted in Prism 6 (GraphPad Software).

\section{RESULTS}

Stimulation with LPS $(1 \mathrm{ng} / \mathrm{mL})$ from different bacterial sources elicited significantly different concentrations of TNF $\alpha$ $(P<0.001$, one-way RM-ANOVA, Fig. 1A), with "rough"-LPS derived from $S$. minnesota causing significantly greater TNF $\alpha$ release than the 3 "smooth"-LPS sources (all $P<0.01$, Tukey). Cytokine release was further altered by the use of alternate anticoagulants $(P<0.001$, one-way RM-ANOVA) being significantly lower when EDTA was employed than either LH or Na Cit (both $P<0.01$, Tukey, Fig. 1C). While incubation of stimulated WB at $37^{\circ} \mathrm{C}$ was necessary-samples at $20^{\circ} \mathrm{C}$ releasing minimal $\mathrm{TNF} \alpha$ (mean $89.27 \mathrm{pg} / \mathrm{mL}$, Fig. 1E) —no significant difference was observed between agitated (mean 4,049 pg/mL, SD 1653) and nonagitated samples $(4,459 \mathrm{pg} / \mathrm{mL}$, SD $1967 ; P=0.15$, paired $t$ test). Stimulation with either increasing doses of LPS (S. abortus equi), or for variable periods of time, predictably led to differential concentrations of TNF $\alpha$ in the supernatant when aspirated; $1 \mathrm{ng} / \mathrm{mL}$ and incubation time $>4 \mathrm{~h}$ leading to maximal or equivalent responses (Fig. 1B and D). Spontaneous production of TNF $\alpha$ in un-stimulated blood was not observed.

Variations in sample handling prior to LPS stimulation caused discrepancies in assayed TNF $\alpha$. Both time to LPS addition and storage temperature significantly effected supernatant TNF $\alpha$ concentration (both $P<0.001,2$-way RM ANOVA), increasing time leading to lower release and $20^{\circ} \mathrm{C}$ storage eliciting significantly greater release than either $4^{\circ} \mathrm{C}$ or $37^{\circ} \mathrm{C}$ (both $P$ $<0.001$, Tukey). No significant interaction was observed between the two variables $(P=0.2)$. Predilution of blood, for ease of technical performance and to enhance supernatant yield, as expected, leads to a fall in $\mathrm{TNF} \alpha$ concentration per unit supernatant with an increased ratio of media to WB (Fig. 2A). This decrease was however not directly proportional, normalization by dilution factor failing to create equivalence between technical approaches $(P<0.01$, one-way RM-ANOVA).

Considerable interindividual variation in LPS-stimulated $\mathrm{TNF} \alpha$ release was observed, the supernatant of heparinized blood from 10 volunteers stimulated with $1 \mathrm{ng} / \mathrm{mL} S$. abortus equi $\left(6 \mathrm{~h}, 1: 5\right.$ dilution, $37^{\circ} \mathrm{C}$, agitated) having measured concentrations ranging from 1,024 to 4,649 pg/mL (mean 2,339 pg/ $\mathrm{mL}$, Fig. 2B). Expression of assayed TNF $\alpha$ as a function of cell number ( $\mathrm{pg} / \mathrm{mL}$ per 1,000 monocytes) rather than as an absolute concentration in supernatant $(\mathrm{pg} / \mathrm{mL})$ resulted in a decrease in the co-efficient of variation (39.95\% vs. $47.17 \%$ respectively, Fig. 2B). The addition of a cyclooxygenase inhibitor to the assay both decreased the co-efficient of variation $(37.67 \%$ vs. $47.17 \%$ ) and significantly increased the measured TNF $\alpha$ concentration (panel A, Supplemental Figure 1, Supplemental Digital Content 1, at http://links.lww.com/SHK/A358; LPS alone mean $2339 \mathrm{pg} / \mathrm{mL}$, NSAID LPS $3108 \mathrm{pg} / \mathrm{mL}$, $P<0.001$, RM $t$ test). Normalization of these values by monocyte count further reduced the co-efficient of variation (32.09\%, Panel B, Supplemental Figure 1, Supplemental Digital Content 1, at http://links.lww.com/SHK/A358). While intra-individual variation in serially assessed $\mathrm{TNF} \alpha$ release was additionally noted, the statistical significance of this was not tested (panel C, Supplemental Figure 1, Supplemental Digital Content 1, at http://links.lww.com/SHK/A358).

\section{DISCUSSION}

Ex vivo LPS-stimulated WB TNF $\alpha$ release is a biomarker of monocyte function and reflective of global immune competence, persistent reduction being predictive of adverse outcomes, and its restoration an indicator of clinical improvement $(4,9,10,13)$. However, to date, laboratories have employed divergent techniques to determine and report this key metric (see Table 1) (14-18), impairing interpretation, comparability, and reproducibility. No clear rationale underlies these alternate approaches.

Selection of LPS source, LPS concentration, duration and temperature of incubation, anticoagulant and decision to dilute the blood varied extensively between laboratories, and were all demonstrated to significantly alter the assay result. Sample handling prior to stimulation, rarely reported in manuscripts, was additionally observed to contribute variance-both time to LPS addition and WB storage temperature- impacting subsequent TNF $\alpha$ release. Reporting inconsistencies further obfuscate results, studies presenting either concentration of $\mathrm{TNF} \alpha$ alone (4) or expressing this as a factor of cell number (total WBC count (19), monocyte count (12)), and failing to describe the number of biological and/or technical repeats undertaken per time-point/condition per individual. Both normalizing $\mathrm{TNF} \alpha$ concentration to monocyte count and pretreatment of 

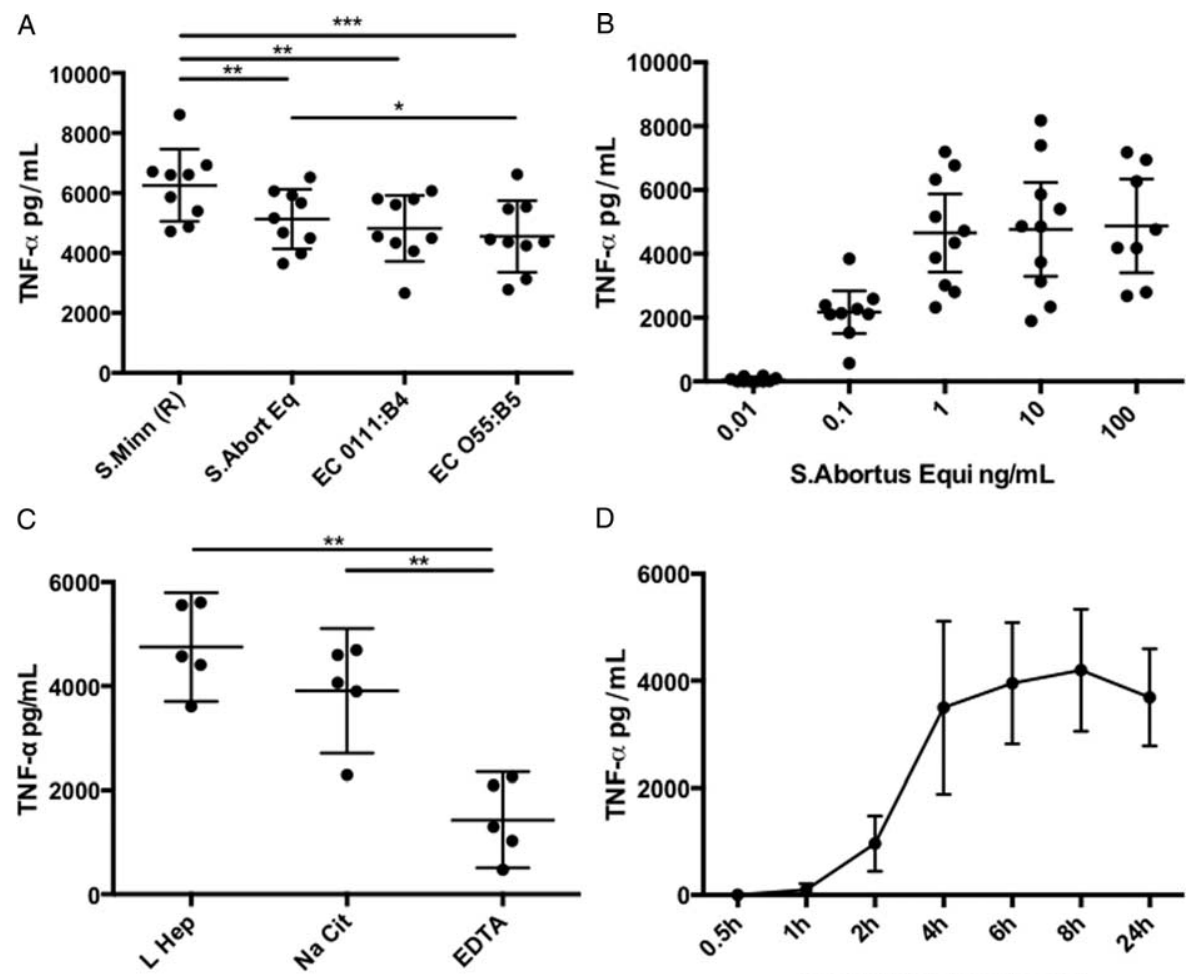

D

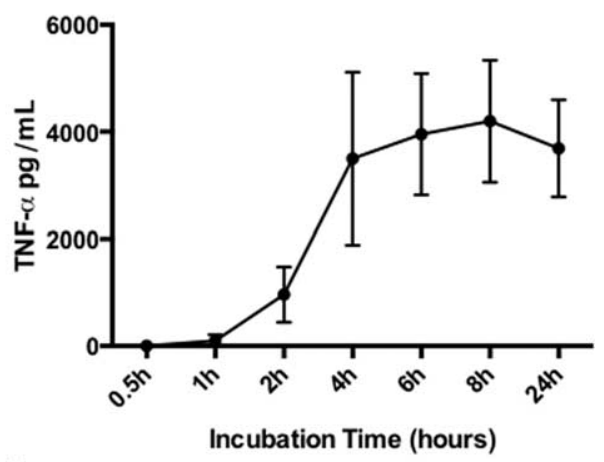

$\mathrm{E}$

$\mathrm{F}$
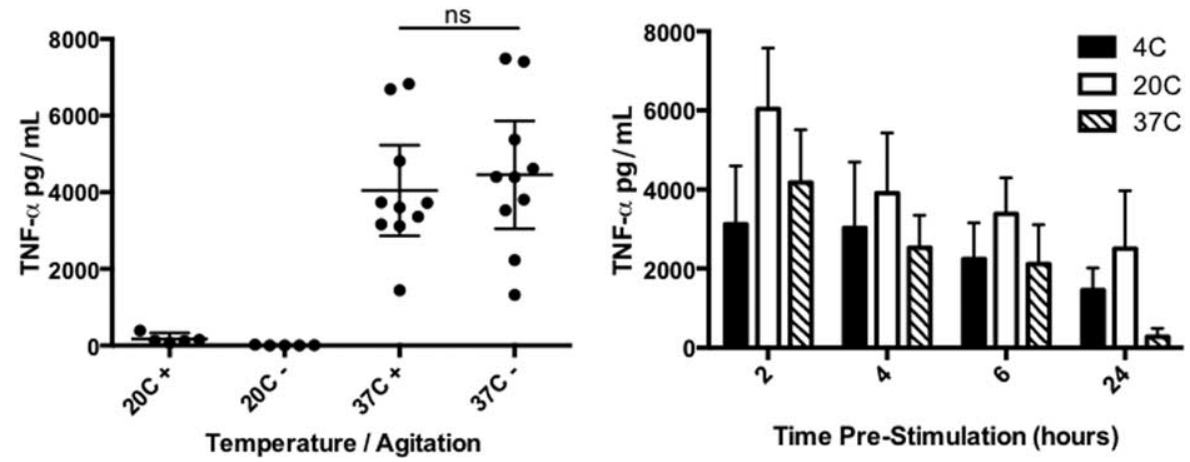

FIG. 1. Effect of discrete variables on the ex vivo lipopolysaccharide (LPS)-stimulated whole blood (WB) cytokine release assay. WB (1 mL) from healthy volunteers was stimulated in triplicate with (A) LPS $(1 \mathrm{ng} / \mathrm{mL}$ ) from four different bacterial sources (Escherichia coli 0111:B4 and 055:B5, Salmonella abortus equi S-form [SAE], Salmonella Minnesota R-form serotype: R595). TNF $\alpha$ from un-stimulated cells was undetectable. B, $n=9$. Different concentrations of LPS (SAE, $10 \mathrm{pg} / \mathrm{mL}$ to $100 \mathrm{ng} / \mathrm{mL}$ ). $C, n=10$. Alternate anticoagulants: lithium heparin, sodium citrate or EDTA (all SAE, $1 \mathrm{ng} / \mathrm{mL}$ ). D, $n=5$. For different lengths of time prior to supernatant removal (SAE, $1 \mathrm{ng} / \mathrm{mL}, 30 \mathrm{~min}$ to $24 \mathrm{~h})$. $\mathrm{E}, \mathrm{n}=5$. In alternate incubation conditions either $20^{\circ} \mathrm{C}$ or $37^{\circ} \mathrm{C}$, with $(+)$ or without $(-)$ agitation. $\mathrm{F}, \mathrm{n}=10$. Variations in sample handling (time to stimulation $[2,4,6,12 \mathrm{~h}]$ and storage temperature $\left[4^{\circ} \mathrm{C}, 20^{\circ} \mathrm{C}, 37^{\circ} \mathrm{C}\right]$ ). $\mathrm{n}=5 \mathrm{per}$ condition. Lines denote mean and $95 \%$ confidence intervals. Differences between categorical variables were tested for using either repeated measures one-way or two-way analysis of variance with Tukey multiple comparisons test, or paired $t$ tests. Statistical significance is indicated as ${ }^{\star} P<0.05,{ }^{\star \star} P<0.01,{ }^{\star \star \star} ~ P<0.001$. EDTA indicates ethylenediaminetetraacetic acid; ns, non-significant; TNF $\alpha$, tumor necrosis factor $\alpha$.

the blood with a cyclooxygenase inhibitor were found to synergistically reduce the coefficient of variation; however, the functional and diagnostic relevance of this is unclear.

These results are not unexpected. It has long been known that varying the LPS dose or duration of incubation alters the readout of the ex vivo WB assay $(14,15)$. Nor is it surprising that sample handling, different sources of LPS, dilution of the blood, or choice of anticoagulant alters measured TNF $\alpha$ concentrations. What is remarkable however is the lack of derivation and adoption of a uniform method and reporting standard for this important test of immune dysfunction: a deficiency that needs to be addressed. Stratified immunoadjuvant therapy holds great promise for critically ill patients
$(3,20)$. Establishing a panel of biomarkers with associated clinically relevant definitions and predictive value, to determine who to treat, when to treat them, and what to administer will be critical to its success (21). It is vital that avoidable methodological heterogeneity does not confound inclusion criteria, determination of outcome, and thus the external validity of future clinical trials.

It should be noted that this study was not designed to define a "gold-standard" method of undertaking the ex vivo WB stimulation assay, instead seeking to identify key sources of methodological variance and highlight their implications. Participants were healthy volunteers, a "core" method was selected and only one method of $\mathrm{TNF} \alpha$ measurement was 




B

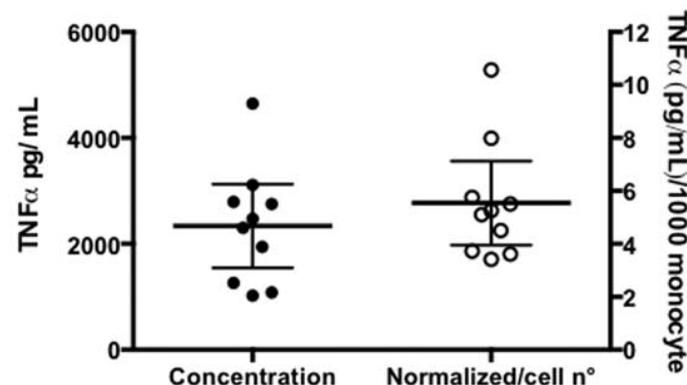

FIG. 2. Variations in reporting convention of data from the ex vivo LPS-stimulated WB cytokine release assay. A, Left panel—WB (1 mL) was stimulated $(S A E, 1 \mathrm{ng} / \mathrm{mL})$ either un-diluted or prediluted with RPMI at a 1:1, 1:5, or 1:10 ratio. $\mathrm{n}=10$ per condition. Right panel-measured concentrations were normalized by dilution factor to examine for equivalence. Lines denote mean and $95 \%$ confidence intervals. Differences were tested for using repeated measures one-way analysis of variance with Tukey multiple comparisons test. Statistical significance is indicated as ${ }^{*} P<0.05,{ }^{* *} P<0.01$. B, TNF $\alpha$ expressed as either an absolute concentration in aspirated supernatant or as a factor of cell number (/1000 monocytes). $n=10$. TNF $\alpha$ indicates tumor necrosis factor $\alpha$; WB, whole blood.

performed. Response variation may have differed had an alternate system and population been employed. In particular, the importance of normalizing $\mathrm{TNF} \alpha$ release to monocyte count-more variable in acute illness-to accurately gauge immune competence may have been underestimated. The blood collection tubes employed were sterile and from one batch, yet not guaranteed to be pyrogen free. Additional technical factors not elaborated here may also impact measured $\mathrm{TNF} \alpha$ release including the method of LPS extraction, purification and solubilization, and the testing of either fresh or frozen supernatants. Future work may address these deficiencies and should seek to formulate and validate the predictive and diagnostic value of a standardized assay-in conjunction with additional metrics of immunosuppression-as a clinical imperative.

TABLE 1. Heterogeneity in methodology employed to perform the ex vivo lipopolysaccharide (LPS)-stimulated whole blood cytokine release assay

\begin{tabular}{|c|c|c|c|c|c|c|c|c|}
\hline & $\begin{array}{c}\text { Ertel } \\
1995(14)\end{array}$ & $\begin{array}{c}\text { Ogata } \\
2000(16)\end{array}$ & $\begin{array}{c}\text { Wang } \\
2000(15)\end{array}$ & $\begin{array}{c}\text { Heagy } \\
2003(17)\end{array}$ & $\begin{array}{l}\text { Ploder } \\
2006 \text { (9) }\end{array}$ & $\begin{array}{c}\text { Allen } \\
2006(18)\end{array}$ & $\begin{array}{c}\text { Hall } \\
2011(10)\end{array}$ & $\begin{array}{c}\text { Kox } \\
2011(12)\end{array}$ \\
\hline LPS type & E. Coli 055:B5 & E. Coli $127: B 8$ & E. Coli 026:B7 & E. Coli 0111:B4 & S. Abortus Equi & N. Meninigitides & S. Abortus Equi & E. Coli O55:B5 \\
\hline LPS concentration & $1 \mathrm{ng}$ to $1 \mu \mathrm{g} / \mathrm{mL}$ & $10 \mathrm{ng} / \mathrm{mL}$ & $10 \mathrm{ng} / \mathrm{mL}$ & $10 \mathrm{ng} / \mathrm{mL}$ & $500 \mathrm{pg} / \mathrm{mL}$ & $10 \mu \mathrm{g} / \mathrm{mL}$ & $500 \mathrm{pg} / \mathrm{mL}$ & $1 \mathrm{ng} / \mathrm{mL}$ \\
\hline Diluent type & None & Saline & None & RPMI & RPMI & RPMI & $\mathrm{NI}$ & RPMI \\
\hline Blood /diluent (ratio) & $5 \mathrm{~mL} / 0(\mathrm{~N} / \mathrm{A})$ & $\mathrm{NI} / 5 \times(1: 5)$ & $\mathrm{NI} / 0(\mathrm{~N} / \mathrm{A})$ & $\begin{array}{c}1-3 \mathrm{~mL} / 0 \\
(\mathrm{~N} / \mathrm{A})\end{array}$ & $50 \mu \mathrm{L} / 0(\mathrm{~N} / \mathrm{A})$ & $\begin{array}{c}500 \mu \mathrm{L} / 500 \mu \mathrm{L} \\
(1: 1)\end{array}$ & $\begin{array}{c}50 \mu \mathrm{L} / 500 \mu \mathrm{L} \\
(1: 10)\end{array}$ & $\begin{array}{c}1 \mathrm{~mL} / 4 \mathrm{~mL} \\
(1: 5)\end{array}$ \\
\hline Incubation/agitation & $1-24 \mathrm{~h} /$ yes & $4 \mathrm{~h} / \mathrm{NI}$ & $2-24 \mathrm{~h} /$ yes & $3 \mathrm{~h} /$ yes & $4 \mathrm{~h} / \mathrm{NI}$ & $24 \mathrm{~h} / \mathrm{NI}$ & $4 \mathrm{~h} / \mathrm{NI}$ & $24 \mathrm{~h} / \mathrm{NI}$ \\
\hline Anticoagulant & Heparin & Heparin & Citrate & Heparin & Heparin & Heparin & Heparin & Heparin \\
\hline $\begin{array}{l}\text { Sample handling } \\
\text { (time/temp.) }\end{array}$ & $\mathrm{NI} / \mathrm{NI}$ & $\mathrm{NI} / \mathrm{NI}$ & $\mathrm{NI} / \mathrm{NI}$ & $\mathrm{NI} / \mathrm{NI}$ & $\mathrm{NI} / \mathrm{lce}$ & $\mathrm{NI} / \mathrm{NI}$ & $1 \mathrm{~h} / \mathrm{NI}$ & $\mathrm{NI} / \mathrm{NI}$ \\
\hline TNF $\alpha$ quantification & Bioassay & $\mathrm{NI}$ & EIA and bioassay & ELISA & Chemi-luminescence & $\mathrm{NI}$ & Chemi-luminescence & Luminex Assay \\
\hline Results expression & $\begin{array}{r}\mathrm{U} / \mathrm{mL} / 1 \times 10^{6} \\
\text { monocytes }\end{array}$ & $\mathrm{U} / \mathrm{mL}$ & $\mathrm{pg} / \mathrm{mL}$ & $\mathrm{pg} / \mathrm{mL}$ & $\mathrm{ng} / \mathrm{mL}$ & $\mathrm{pg} / \mathrm{mL}$ & $\mathrm{pg} / \mathrm{mL}$ & pg/1000 monocytes \\
\hline Indicative results & $535.9 \pm 75$ & $240 \pm 36$ & $1,449-2,484$ & $6,706 \pm 715$ & $1.05-2.8$ & $900 \pm 50$ & $900-2,172$ & $55 \pm 5$ \\
\hline
\end{tabular}

Eight published papers (first author, year of publication) were selected to exemplify diversity in technical performance of the assay along key variables (LPS type and concentration, use of diluent and ratio to blood, incubation period after stimulation [all at $37^{\circ} \mathrm{C}$ ], use of agitation during this period, choice of anticoagulant), sample handling prior to analysis (time and storage temperature from collection to stimulation) method of tumor necrosis factor $\alpha$ (TNF $\alpha$ ) measurement and reporting of results (absolute TNF $\alpha$ concentration in supernatant or whether normalized to cell number). The range, mean or median ( \pm SEM or IQR respectively) of TNF $\alpha$ concentrations reported in the control group in each study is also displayed.

ELISA indicates enzyme-linked immunosorbent assay; N/A indicates not applicable; NI, not indicated. 


\section{REFERENCES}

1. Boomer JS, To K, Chang KC, Takasu O, Osborne DF, Walton AH, Bricker TL, Jarman SD 2nd, Kreisel D, Krupnick AS, et al.: Immunosuppression in patients who die of sepsis and multiple organ failure. JAMA 306(23):25942605, 2011.

2. Otto GP, Sossdorf M, Claus RA, Rodel J, Menge K, Reinhart K, Bauer M, Riedemann NC: The late phase of sepsis is characterized by an increased microbiological burden and death rate. Crit Care 15(4):R183, 2011.

3. Leentjens J, Kox M, van der Hoeven JG, Netea MG, Pickkers P: Immunotherapy for the adjunctive treatment of sepsis: from immunosuppression to immunostimulation. Time for a paradigm change? Am J Respir Crit Care Med 187(12):1287-1293, 2013.

4. Docke WD, Randow F, Syrbe U, Krausch D, Asadullah K, Reinke P, Volk HD, Kox W: Monocyte deactivation in septic patients: restoration by IFN-gamma treatment. Nat Med 3(6):678-681, 1997.

5. Meisel C, Schefold JC, Pschowski R, Baumann T, Hetzger K, Gregor J, WeberCarstens S, Hasper D, Keh D, Zuckermann H, et al.: Granulocyte-macrophage colony-stimulating factor to reverse sepsis-associated immunosuppression: a double-blind, randomized, placebo-controlled multicenter trial. Am J Respir Crit Care Med 180(7):640-648, 2009.

6. Monneret G, Lepape A, Voirin N, Bohe J, Venet F, Debard AL, Thizy H, Bienvenu J, Gueyffier F, Vanhems P: Persisting low monocyte human leukocyte antigen-DR expression predicts mortality in septic shock. Intensive Care Med 32(8): 1175-1183, 2006.

7. Landelle C, Lepape A, Voirin N, Tognet E, Venet F, Bohe J, Vanhems P, Monneret G: Low monocyte human leukocyte antigen-DR is independently associated with nosocomial infections after septic shock. Intensive Care Med 36(11):1859-1866, 2010.

8. Appoloni O, Vincent JL, Duchateau J: Response of tumour necrosis factor-alpha to delayed in vitro monocyte stimulation in patients with septic shock is related to outcome. Clin Sci (Lond) 102(3):315-320, 2002.

9. Ploder M, Pelinka L, Schmuckenschlager C, Wessner B, Ankersmit HJ, Fuerst W, Redl H, Roth E, Spittler A: Lipopolysaccharide-induced tumor necrosis factor alpha production and not monocyte human leukocyte antigen-DR expression is correlated with survival in septic trauma patients. Shock 25(2):129-134, 2006.
10. Hall MW, Knatz NL, Vetterly C, Tomarello S, Wewers MD, Volk HD, Carcillo JA: Immunoparalysis and nosocomial infection in children with multiple organ dysfunction syndrome. Intensive Care Med 37(3):525-532, 2011.

11. Demaret J, Walencik A, Jacob MC, Timsit JF, Venet F, Lepape A, Monneret G: Inter-laboratory assessment of flow cytometric monocyte HLA-DR expression in clinical samples. Cytometry B Clin Cytom 84(1):59-62, 2013.

12. Kox M, de Kleijn S, Pompe JC, Ramakers BP, Netea MG, van der Hoeven JG, Hoedemaekers CW, Pickkers P: Differential ex vivo and in vivo endotoxin tolerance kinetics following human endotoxemia. Crit Care Med 39(8):1866-1870, 2011.

13. Nierhaus A, Montag B, Timmler N, Frings DP, Gutensohn K, Jung R, Schneider CG, Pothmann W, Brassel AK, Schulte Am Esch J: Reversal of immunoparalysis by recombinant human granulocyte-macrophage colony-stimulating factor in patients with severe sepsis. Intensive Care Med 29(4):646-651, 2003.

14. Ertel W, Kremer JP, Kenney J, Steckholzer U, Jarrar D, Trentz O, Schildberg FW: Downregulation of proinflammatory cytokine release in whole blood from septic patients. Blood 85(5):1341-1347, 1995.

15. Wang JE, Solberg R, Okkenhaug C, Jorgensen PF, Krohn CD, Aasen AO: Cytokine modulation in experimental endotoxemia: characterization of an ex vivo whole blood model. Eur Surg Res 32(2):65-73, 2000.

16. Ogata M, Okamoto K, Kohriyama K, Kawasaki T, Itoh H, Shigematsu A: Role of interleukin-10 on hyporesponsiveness of endotoxin during surgery. Crit Care Med 28(9):3166-3170, 2000.

17. Heagy W, Nieman K, Hansen C, Cohen M, Danielson D, West MA: Lower levels of whole blood LPS-stimulated cytokine release are associated with poorer clinical outcomes in surgical ICU patients. Surg Infect (Larchmt) 4(2):171-180, 2003.

18. Allen ML, Hoschtitzky JA, Peters MJ, Elliott M, Goldman A, James I, Klein NJ: Interleukin-10 and its role in clinical immunoparalysis following pediatric cardiac surgery. Crit Care Med 34(10):2658-2665, 2006.

19. Woiciechowsky C, Asadullah K, Nestler D, Schoning B, Glockner F, Docke WD, Volk HD: Diminished monocytic HLA-DR expression and ex vivo cytokine secretion capacity in patients with glioblastoma: effect of tumor extirpation. J Neuroimmunol 84(2):164-171, 1998.

20. Hutchins NA, Unsinger J, Hotchkiss RS, Ayala A: The new normal: immunomodulatory agents against sepsis immune suppression. Trends Mol Med 20(4):224-233, 2014

21. Hamers L, Kox M, Pickkers P: Sepsis-induced immunoparalysis: mechanisms, markers, and treatment options. Minerva Anestesiol 81(4):426-439, 2015.
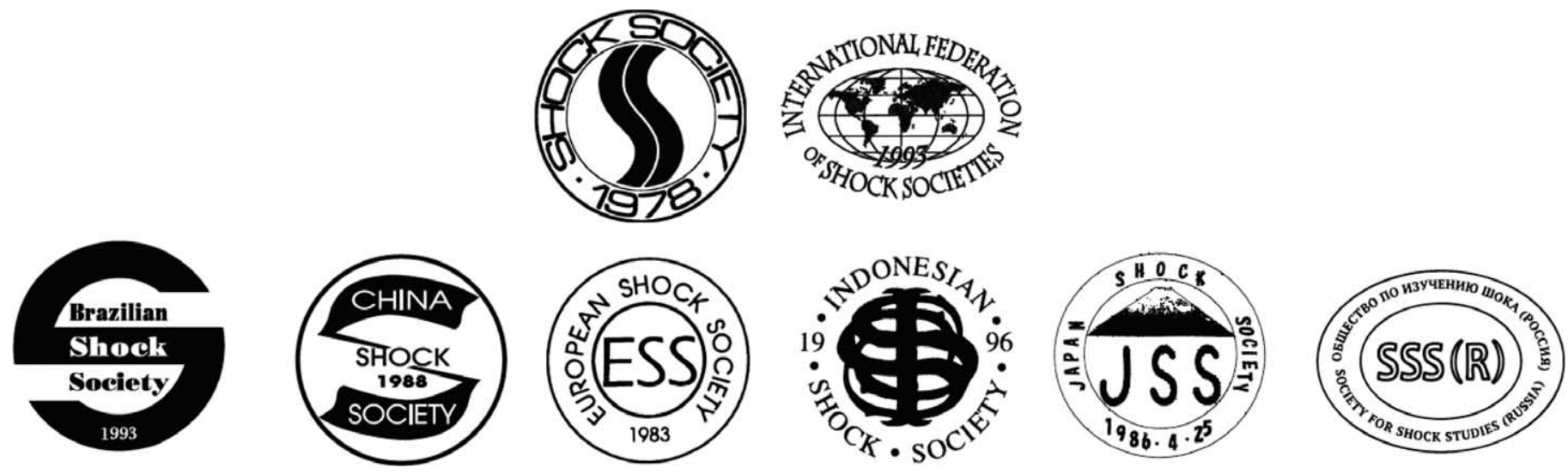

Copyright $@ 2016$ by the Shock Society. Unauthorized reproduction of this article is prohibited. 